\title{
CUBA E A COOPERAÇÃO SUL-SUL: CONTRIBUIÇÕES DE UM REGIME SOCIALISTA A CID?
}

\section{Cuba and South-South Cooperation: Any contribution of a socialist regime to IDC?}

\author{
Marina Bolfarine Caixeta ${ }^{1}$
}

\begin{abstract}
"Ali onde governa, deve-se atender ao que existe, para governar bem; e o bom governante na América não é aquele que sabe como o alemão governa ou o francês, mas o que sabe com que elementos que seu país está composto e como pode ir guiando-os unidos para chegar, por métodos e instituições nascidas do próprio país, àquele estado desejável onde cada homem se conhece e se exercita, e desfrutam todos da abundância que a natureza colocou para todos no povo que fecundam com o seu trabalho e defendem com as suas vidas. O governo tem que nascer do país. O espírito do governo tem que ser do país. A forma de governo tem que se ajustar à constituição própria do país. O governo não é mais do que o equilíbrio dos elementos naturais do país" (Martí, 2011).
\end{abstract}

\section{Introdução}

No século XIX, aspirava-se à libertação dos países colonizados. No século XX, falava-se em revolução de largas proporções na América Latina e Caribe. Desde o momento em que se deu o encontro dos mundos, movimentos libertários evidenciaram o grau de opressão do sistema de dominação europeu - falase da transformação do sistema colonial no presente colonialismo do poder, do saber e do ser. ${ }^{2}$ Desde os primórdios da emergência de um pensamento crítico nas colônias americanas, ansiava-se pelo reconhecimento da singularidade das realidades e povos que aqui viviam e sua dignidade humana.

A aproximação atual entre países periféricos na política internacional, o que conforma o Sul global, é uma tendência desejável e natural. Há um passado histórico comum que une esses povos e nações em torno dos fenômenos sociais da miscigenação biológica e cultural, da construção de uma identidade

\footnotetext{
${ }^{1}$ Mestre pelo Programa de Pós-Graduação em Desenvolvimento, Sociedade e Cooperação Internacional - CEAM da Universidade de Brasília; especialista em Desenvolvimento Sustentável - CDS da Universidade de Brasília e bacharel em Relações Internacionais pela Universidade Católica de Brasília. Email: marinabolfarinecaixeta@gmail.com

${ }^{2}$ Ballestrín (2013) conta a trajetória e o pensamento do Grupo Modernidade/Colonialidade (M/C) latino-americano que realizou um movimento epistemológico fundamental para a renovação crítica e utópica das ciências sociais na América Latina no século XXI: a radicalização do argumento pós-colonial no continente por meio da noção de "giro decolonial”.
} 
nacional e dos desafios políticos trazidos pela inserção dependente no cenário global e pelo desenvolvimento do subdesenvolvimento ${ }^{3}$.

A cooperação Sul-Sul (CSS) é fenômeno social, econômico e político desse contexto global e uma nova tendência da cooperação internacional para o desenvolvimento (CID) (CAIXETA, 2014). Ela surge como estratégia autonomista e de sentido horizontal de base intercultural e plural. Possui o objetivo de construir uma nova ordem internacional mais igualitária e justa e de unir os atores em torno dos desafios estruturais ligados ao desenvolvimento dos povos. A CSS enseja, nesse sentido, o resgate dessa identidade comum no Sul global e a operação cojunta no âmbito político internacional.

A América Latina e o Caribe (ALC) se classifica como região que se encontra no meio do percurso do desenvolvimento - vide os indicadores econômicos (como o PIB) e sociais (como o IDH). Ao mesmo tempo que é beneficiária histórica de recursos externos direcionados a políticas de desenvolvimento, a região possui, em quase sua totalidade, países considerados como de renda média (PRM) ${ }^{4}$. Isso justifica a diminuição da entrada de recursos e um discurso em prol da maior responsabilização desses países como provedores de iniciativas de CID por intermédio da CSS. No entanto, a Comissão Econômica para a América Latina e o Caribe (CEPAL) no relatório "Horizonte 2030" alerta para uma recente desaceleração preocupante na região provocada pela diminuição da Assistência Oficial ao Desenvolvimento (AOD) da OCDE (CEPAL, 2016).

As atuais discussões em torno da implementação da nova agenda de desenvolvimento global, a Agenda 2030, trazem o reconhecimento do potencial da cooperação Sul-Sul para a CID ${ }^{5}$. Instrumentalizada pelos Objetivos de Desenvolvimento Sustentáveis (ODS), as ações no bojo da CID estão sendo repensadas à luz de experiências inovadoras e bem sucedidas de CSS. O discurso do ex-Secretário-Geral da ONU, Ban KiMoon, no dia da Cooperação Sul-Sul (12 de setembro), denota sua importância para a agenda global e a reconhece como manifestação solidária entre os países em desenvolvimento. ${ }^{6}$

Cada vez com mais frequência, os países em desenvolvimento trocam experiências de sucesso sobre soluções próprias para seus problemas comuns. Apesar da inexistência de uma coordenação no nível internacional para classificar e contabilizar as iniciativas de Cooperação Sul-Sul (CSS) ${ }^{7}$, o relatório do

\footnotetext{
${ }^{3}$ Gunder-Frank (1970) pela expressão "desenvolvimento do subdesenvolvimento" chama atenção para o fato de que o subdesenvolvimento dos países é produto histórico de um modelo econômico que está estruturado por "satélites subdesenvolvidos" e "metropolitanos desenvolvidos". O sistema capitalista na escala global aponta para a tendência de desenvolver as metrópoles e subdesenvolver as periferias.

${ }^{4}$ Segundo Ayllón (2014), à exceção do Haiti, a América Latina passou da condição de eminente receptora das iniciativas de cooperação, no presente século, para um papel mais ativo no cenário da CID. Essa evolução está atrelada à formulação de agenda própria de cooperação internacional (Cooperação Sul-Sul), ao reconhecimento de capacidades técnicas instaladas, à posição mais autônoma no cenário geopolítico e econômico, com presença em importantes blocos de negociação (BRICS, G20, G77) e, também, à mobilização crescente de recursos públicos dedicados para a CID.

${ }^{5}$ Destaque deve ser dado a South-South Expo de Dubai, em novembro de 2016, que teve o intuito de identificar práticas inovadoras e casos de sucesso para a implementação dos Objetivos de Desenvolvimento Sustentável.

${ }^{6}$ ONU (2016). Disponível em: http://www.un.org/en/events/southcooperationday/2016/sgmessage.shtml

${ }^{7}$ Sabe-se que inexiste uma metodologia única para estimar o montante de recursos investidos em práticas da cooperação Sul-Sul, no moldes do Comitê de Assistência do Desenvolvimento (CAD) da Organização para a Cooperação e o Desenvolvimento Econômico (OCDE); além disso, inexiste um conceito único sobre a CSS pelos próprios países mais ativos dessa agenda, como os países emergentes (China, Turquia, Brasil, Índia, África do Sul), o que impede de identificar o que deve ser contabilizado e o que não deve, com fins de comparação entre países.
} 
Secretario-Geral da ONU de 2014 informou que a participação da CSS na CID cresceu de 6,7\% em 2006 para $10 \%$ em $2011 .{ }^{8}$

Cuba, em especial, se caracteriza pela sua significativa participação em iniciativas da cooperação Sul-Sul. Apesar das dificuldades de financiamento para o desenvolvimento interno, Cuba integra o grupo dos 5 países mais ativos que ofertam ações de cooperação Sul-Sul bilateral para outros países da região da América Latina e Caribe (SEGIB, 2016) ${ }^{9}$. Notadamente, o país se destaca em temas sociais como a saúde pública e educação. Adicionalmente, Cuba apresenta iniciativas de CID que se reforçam os princípios da cooperação Sul-Sul.

Desde a Revolução socialista de 1959, o país prioriza as relações com os países do Sul global. Seja pelo apoio armado e de brigadas médicas às lutas pela independência na África - Argélia, Angola, Guiné Bissau, RDC dentre outros - ou apoio político às lutas nacionalistas de lideranças indígenas - Bolívia, Venezuela, Equador, Guatemala, México-Chiapas; seja pela acolhida desses povos nos centros médicos e escolas em Cuba. Além disso, reforça-se o discurso da autonomia contra as ações imperialistas nos fóruns multilaterais e evidenciam-se motivações solidárias nas iniciativas de ajuda emergencial aos países e povos acometidos por catástrofes, conforme relata Fidel Castro (RAMONET, 2006).

Este artigo, dessarte, pretende discutir as contribuições cubanas à CSS, de um regime socialista de governo que estendeu para além de suas fronteiras sua atuação em prol de desenvolvimentos nacionais e defendeu o papel do Estado na promoção de bem-estar social. Na primeira seção, buscam-se alguns elementos históricos que explicam e caracterizam um regime socialista de governo. Na segunda seção, propõe-se analisar a política externa cubana e seu envolvimento com a cooperação internacional para o desenvolvimento. Na terceira seção, discorre-se sobre as duas principais iniciativas cubanas de CSS em matéria de saúde pública, a saber: o envio de médicos cubanos para outros países e a formação de médicos estrangeiros na Escola Latino-Americana de Medicina (ELAM). Ao final, apresentam-se reflexões como contribuição às seguintes indagações: Poder-se-ía alçar Cuba e suas iniciativas de CSS como importantes fontes para as discussões sobre inovação das iniciativas de CID na Agenda 2030? Seria possível relacionar o socialismo a uma cooperação internacional horizontal mais comprometida com políticas de desenvolvimento nacional? Pode-se esperar que a CID no seio do capitalismo global realize os objetivos da atual agenda global 2030 e que a CSS, como um tipo de CID, melhor trate dos desafios enfrentados pelos países em desenvolvimento?

\section{A Revolução e os ideiais socialistas cubanos}

Sem a pretenção de narrar ou mesmo de analisar o que foi a revolução cubana, um evento de tão grande importância para o mundo e sobretudo para a América Latina e o Caribe, apresentam-se, nesta contextualização, alguns elementos e fatos históricos para a compreensão da singularidade de Cuba no presente cenário global.

\footnotetext{
${ }^{8}$ Relatório ECOSOC E/2014/77 disponível em: https://www.un.org/ecosoc/sites/www.un.org.ecosoc/files/publication/n1440507.pdf. Acesso em 20 de dezembro de 2016

${ }^{9}$ Registra-se, contudo, que desde 2012, quando a SEGIB refinou sua metodologia de contabilização dos dados, Cuba tem sido omissa no envio dos dados, conforme aponta Gómez (2016).
} 
Com base em ideiais de libertação nacional, Winocur (1989) periodiza a história cubana em 4 fases: colonial (1868-1902), república semicolonial (1902-1959), república democrática (1952-1959) e república socialista (a partir de 1960). Ao longo dessa história pode-se dizer que havia um projeto invariável: a emancipação nacional. Para persegui-la, entretanto, articula-se a linha fundamental das contradições evidenciadas nesses diferentes períodos: ser ou não contra as populações dominadoras de fora do país.

A luta contra os exploradores do exterior, segundo Winocur (1989), revela que a queda de Fulgencio Batista era parte do projeto de libertação nacional. No entanto, os 7 anos que marcam o período da revolução democrática, de 1952 a 1959, alcançaram o que se tentou em quase um século, de 1868 a 1960. Após a tomada do poder pelo exército rebelde, incia-se a revolução socialista, como projeto vitorioso em meio a novas contradições. Contra os exploradores de dentro, decratam-se as nacionalizações do capital nativo e empreende-se a reforma urbana e agrária.

Não se pode omitir que Cuba contou com um grande legado revolucionário de José Martí, um dos mais proeminentes intelectuais engajados na região. Martí está associado à construção da pátria liberta e à serviço da sua população com reverberações em toda a região latino-americana. Cuba foi um país pioneiro na América Latina e Caribe, pois contava com um partido organizado com propósitos revolucionários. Em 1891, a criação do Partido Revolucionário Cubano aproxima José Martí de Lenin, com a diferença que o caso cubano tratava de uma frente nacional multiclassista e não exclusivamente baseada no proletariado como o caso soviético. As bases do partido cubano quase que se confundem com o projeto revolucionário de Martí, um democrata que tratou sobre a guerra como procedimento político, a gestão antiimperialista, a fundação de uma nação em benefício de seu povo, a batalha social a favor dos pobres da terra, a revolução a ser desenvolvida no seio de uma república, a transcendencia internacional, conforme epígrafe deste artigo (RETAMAR, 2016).

A Revolução Socialista de 1959 com a liderança de Fidel Castro dá continuidade ao projeto revolucionário de José Martí de 1894. Segundo Guevara (2014), a guerra revolucionária que aconteceu em Cuba compõe a trilogia de movimentos progressistas no mundo, juntamente às revoluções russa de $1917 \mathrm{e}$ chinesa de 1949. Cuba não seria uma exceção histórica a reunir condições de vivenciar uma revolução socialista, ainda que conte com características peculiares, mas antes a vanguarda de uma luta anticolonialista que todos os povos latino-americanos esperavam alcançar em suas lutas autonomistas e desenvolvimentistas. $\mathrm{O}$ antiimperialismo une a todos os povos latino-americanos devido a sua condição de países subdesenvolvidos, colonizados e sob o domínio do império norte-americano.

O caráter global de tais revoluções se justificariam face ao imperialismo capitalista ${ }^{10}$. Esse contexto aproxima os povos da América Latina, África e Ásia e, ao mesmo tempo, diferencia os latino-americanos. As formas de exploração econômica imperialista pela burguesia europeia aqui foram intensificadas pela

\footnotetext{
${ }^{10}$ Cabe ressaltar que às críticas ao imperialismo será muito forte nos discursos pós-revolucionários de Cuba, em sintonia com o trabalho de Lênin de cuja teoria do imperialismo no bojo das questões apontadas por Marx o conceito tem sido proveniente. Imperialismo ganha um significado negativo após as Revoluções francesa e soviética e se define como a "expansão violenta por parte dos Estados, ou de sistemas políticos análogos, da área territorial da sua influência ou poder direto, e formas de exploração econômica em prejuízo dos Estados ou povos subjugados, geralmente conexas com tais fenômenos - se hajam manifestado, sob formas e modalidades diversas, em todas as épocas da história, esta expressão é relativamente recente.” (BOBBIO, 2010; 611)
} 
penetração dos interesses norte-americanos, o que resultou em classes burguesas nacionais (GUEVARA, 2014).

A influência da Revolução Cubana na América Latina é parte da proposta de irmandade entre os povos (MARTÍ, 2011; GUEVARA, 2014; CASTRO In RAMONET, 2006). Pela sua condição de explorados e seu intuito de subverter o denominador comum de parco progresso que carateriza esses países, pela presença de camponeses explorados, iletrados e alienados, e pela existência de uma burguesia que, ainda que seus interesses sejam muitas vezes contraditórios com os interesses da potência norte-americana, é incapaz de contrariá-lo por medo da sublevação social, muitos são os desafios que unem esses povos no âmbito das agendas globais de desenvolvimento (GUEVARA, 2014).

\section{Solidariedade e Política Externa: a cooperação Sul-Sul cubana}

A política externa cubana considerada é aquela do Estado socialista pós-1959. A implantação do socialistmo em Cuba deve ser analisada tendo como contexto as revoluções do Terceiro Mundo, na década de 1950. Sobre isso, Hobsbawn (1995) comenta que Cuba representou, para muitos, sobretudo para os latino-americanos e caribenhos, o retorno da esperança e fé quanto à possibilidade de uma revolução social em benefício de uma maioria de pessoas prejudicadas com o sistema capitalista.

[...] nenhuma revolução poderia ter sido mais bem projetada para atrair a esquerda do hemisfério ocidental e dos países desenvolvidos, no fim de uma década de conservadorismo global; ou para dar à estratégia da guerrilha melhor publicidade. A revolução cubana era tudo: romance, heroísmo nas montanhas, ex-líderes estudantis com a desprendida generosidade de sua juventude - os mais velhos mal tinham passado dos trinta -, um povo exultante, num paraíso turístico tropical pulsando com os ritmos da rumba. E o que era mais: podia ser saudada por toda a esquerda revolucionária. (HOBSBAWN, 1995 ; 427).

Apesar de não ter raízes marxistas, mas locais, tratava-se de ideologias e ativismo em prol de um sistema socialista no seu sentido mais amplo. Procurava-se socializar as riquezas e benesses da terra (recursos naturais), da economia e da infraestrutura humana. Com isso, entende-se a cooperação Sul-Sul como algo distinto dos ideias internacionalistas da União Soviética para quem as relações externas estavam à serviço da Terceira Internacional Comunista - Kominterm, cujo propósito era reunir os partidos comunistas de diferentes países para a superação do capitalismo a partir da implantação de uma sociedade comunista.

As relações com o Sul global estabelecidas por Cuba adquiriam um caráter próprio: a união de países para a promoção autônoma do desenvolvimento nacional à serviço do bem-estar social. Esse contexto explica a aproximação de Cuba aos demais países em desenvolvimento. Medina (2013) demonstra que os mais de 50 anos de iniciativas de Cuba com o Sul global somam-se à expressividade dessas ações: das causas independentistas da África, movimentos revolucionários da América Latina e Ásia, até o envio de cubanos em apoio à saúde da população de outros países.

No entanto, importante dizer que tanto com base em afinidades ideológicas, quanto com base na solidariedade, Cuba levou à cabo ações de cooperação internacional técnica, médica e econômica. Oramas (2012 apud Medina, 2013; 136) explicita que Cuba prestou ajuda a povos cujos governos possuiam ideologias 
opostas as de Cuba, já que o que estava em questão era atender aos anseios das pessoas. Isso sinaliza a desconexão da cooperação internacional cubana de ações imperialistas, que eram tão criticadas pelos cubanos em seus discursos proferidos na cena internacional.

O bem-estar dos povos eram focalizados em relação à conquista de poder e ao aumento do espaço de influência. Os fundamentos e diretrizes, com o triunfo da revolução socialista, foram elaborados com legitimidade e apoio interno da popoulação cubana. Estreitamente vinculados ao imaginário político, eles convergiam com as grandes mudanças e iniciativas de reconstrução e resgate da solidariedade da nação socialista cubana (MEDINA, 2013).

Deve-se lembrar que a política exterior cubana, no período pós-revolução, serviu como instrumento para o país fazer o mundo conhecer sua posição antiimperialista nos distintos fóruns internacionais. Nesse sentido, notório é o discurso de Che Guevara na Assembleia-Geral das Nações Unidas em 1964, 2 anos após Cuba ser suspensa da Organização dos Estados Americanos (OEA). Nesta ocasião, o Che cubano fala da nova etapa que o mundo vivia com a independência de países africanos e demonstra a importância de garantir a realização plena dos princípios internacionais: direito de autodeterminação dos povos, desenvolvimento independente dos países, coexistência pacífica, não intervenção em assuntos internos. Ele demonstra, citando casos reais da época, a desigualdade existente entre diferentes regimes econômicos-sociais e países com diferentes níveis de poder nos espaços de negociação e sua relação com as iniciativas globais da ONU (GUEVARA, 2014) ${ }^{11}$.

Segundo Medina (2013), a coluna vertebral da política exterior cubana é constituída a partir do internacionalismo, do antiimperialismo, da solidariedade e da integração entre os países do Sul. Como princípios da sua política externa estão: a união com povos em seus esforços de desenvolvimento e de resposta a desastres; colaboração sem condicionamentos, com respeito irrestrito a soberania, leis nacionais, cultura, religião e autodeterminação das nações; recusa de utilizar a colaboração como instrumento político de ingerência nos assuntos internos dos Estados; colaboração baseada em critérios de planejamento e eficiência e as equipes cubanas envolvidas em atividades de colaboração devem ser exemplos dos valores de solidariedade e integridade moral que promove a Revolução Cubana.

Desde meados da década de 1970 até o presente, as parcerias de cooperação cubanas com os países em desenvolvimento está baseada em suas experiências de promover serviços da saúde, educação, desportes sem altos montantes de recursos, tecnologia de ponta sem dependência de recursos, técnicas e conhecimentos de países capitalistas centrais (GONZALEZ, 2011). Adicionalmente, segundo estudo da década de 1990, a estimativa econômica da cooperação cubana direcionada aos países do Terceiro Mundo era a mais elevada - com base da proporção do PIB, Cuba era equiparada aos 18 países mais desenvolvidos e na virada do século eram 141 países que gozavam da assistência técnica cubana (GÓMEZ, 2016).

Conforme Gonzaléz (2011), a aproximação de Cuba com a África significou o reconhecimento da sociedade multirracial cubana e a convergência de ideais antiescravagistas e independentistas. Apesar da

\footnotetext{
${ }^{11}$ Áudio, imagem e texto do discurso de 1964 disponível em: https://www.youtube.com/watch?v=UF9c9FCSvr4
} 
formação da sociedade cubana a partir dos povos africanos desde o século XIX, os vínculos políticos e de outros tipos entre Cuba e os países africanos somente ocorreu com advento da revolução cubana. Sobre isso, Kabunda (2011) explica que a especificidade desta cooperação pós-revolução está baseada na combinação da cooperação civil e militar que dedica mais recursos (em relação ao PIB) do que os países desenvolvidos, dispõe de mais embaixadas na África e acolhe mais representações africanas do que qualquer outro país do mundo.

Com a América Latina, a política exterior cubana caracteriza-se, conforme Medina (2013) por duas etapas. No momento pós-revolucionário, se destaca a escolha por parcerias para fazer frente a política dura e contrária dos Estados Unidos dedicada à Cuba, além da natural convergência com países emergentes da esquerda latino-americana, das necessidades econômicas e comerciais cubanas e das exigências políticas de alguns parceiros significativos, como a União Europeia que colocava obstáculos a Cuba pela sua alegada falta de democracia.

Num segundo momento, inaugurado com o século XXI, as relações da América Latina foram mais favoráveis, devido ao contexto internacional e às iniciativas interamericanas como a ALBA, UNASUL, CELAC. Período marcado pelo abandono do modelo neoliberal, da busca de alternativas ao desenvolvimento autônomo e o interesse por uma estrutura regional de relações multilaterais regionais. Destaque para a aproximação com a Venezuela de que se beneficia no setor econômico e comercial (MEDINA, 2013).

Fala-se de um novo internacionalismo que marca a atual política exterior cubana. Segundo Romero (2015), o primeiro internacionalismo se inicia logo após a Revolução, quando Cuba apoia grupos e processos revolucionários em diversas partes do mundo e o segundo destaca seu envolvimento amplo com a cooperação internacional para o desenvolvimento (CID), além do papel de liderança que desempenha nos fóruns multilaterais em defesa de transformações globais radicais. Trata-se de uma política externa mais direcionada a transformações econômicas e sociais - de planejamento e estrutura da propriedade, de gestão econômica, do sistema empresarial e da política social - que está presente nos marcos jurídico e regulatório do país como a Política Econômica e Social aprovado no VI Congresso do Partido Comunista Cubano (PCC) realizado em abril de 2011 e aprovado pela Assembleia Nacional do Poder Popular (ROMERO, 2015).

Nos último anos, entrentato, Cuba não tem feito parte das concertações globais da CID conhecidas como efetividade da ajuda. A arquitetura global da CID em que a CSS está inserida - Declaração de Paris (2005); Agenda de Accra (2008); Fórum de Busan (2011) - tem se mostrado muito elitista, tecnocrata e atrelada às lógicas da $\mathrm{AOD}$ do Comitê de Assistência ao Desenvolvimento (CAD/OCDE), divergindo dos propósitos da CSS presentes no Plano de Ação de Buenos Aires - PABA (1978) e na Conferência de Nairobi (2009) (GÓMEZ, 2016).

Muito se especula sobre o momento presente com a retomada das relações diplomáticas com os Estados Unidos sob comando de Raúl Castro. Patrício (2017), para quem a liderança de Fidel é elemento central dessa era castrista, fala de possíveis transformações para o futuro próximo, em especial quanto à conjugação da viabilidade econômica com um regime político que atenda aos interesses da diáspora cubana na Flórida que quer voltar a Cuba e estabelecer seus negócios na ilha. 


\section{A saúde em Cuba e de Cuba para o Sul Global}

O acesso aos serviços de saúde é parte dos objetivos de desenvolvimento dos países. Saúde é um tema muito presente nas agendas de desenvolvimento global tanto dos Objetivos de Desenvolvimento do Milênio (ODM) vigente de 2000 a 2015, quanto dos Objetivos de Desenvolvimento Sustentável (ODS), de 2016 até 2030.

Ao colocar em evidência a questão da igualdade de direitos e equidade na oferta de serviços de saúde, Cuba mostra grande avanço em relação a outros países em desenvolvimento e, mesmo, desenvolvidos. Osa (2011) explicita que o sucesso da saúde pública em Cuba após a Revolução está expresso na mudança da taxa de mortalidade infantil, de 60 por 1000 nascimentos para 4,5 por 1000 nascimentos, em 2010, a mais baixa das Américas ${ }^{12}$.

A qualidade da saúde cubana é produto dos princípios e metas do Estado socialista cubano e do objetivo a que se lançou o governo revolucionário: oferecer atendimento sanitário para todos os cidadãos, com especial cuidado a mães e seus filhos, a existência de alto grau de escolaridade da população e um programa nacional de vacinação com uma cobertura de praticamente todas as crianças do país. Adicionalmente, 9 das 15 vacinas administradas à população são produzidas em centros científicos cubanos (OSA, 2011).

A base desse sistema fundamenta-se nos princípios humanitários da saúde pública socialista, a saber: "o Estado, como poder do povo, em serviço do próprio povo, garante que não haja doente sem assistência médica”, explicitado na Constituição da República Cubana - isso aparece tanto nos "Fundamentos Políticos, Sociais e Econômicos do Estado" (artigo $9^{\circ}$ ) quanto nos "Direitos, Deveres e Garantias Fundamentais" (artigo 50) (CUBA, 1992).

O Ministério da Saúde Pública de Cuba, órgão de direção do Sistema Nacional de Saúde, está encarregado do desenvolvimento das ciências médicas e da indústria médico-farmacêutica. O sistema de saúde está estruturado em quatro níveis dando-se grande relevância aos cuidados de saúde primária - no nível primário, há ampla cobertura e baixa complexidade, composto por equipes de saúde básica responsáveis por executar o Programa de Médico de Família. As tomadas de decisões e medidas de promoção de saúde são de competência das estruturas sociais criadas no contexto da revolução cubana: os Comités de Defesa da Revolução. O trabalho de equipe, com abordagem multidisciplinar e integração dos vários níveis é muito evidente tanto no nível da comunidade, como no setor hospitalar (LEE et al., 2005).

No ano de 2002, iniciaram-se os Programas de Revolução em Saúde. As premissas básicas dos programas estão relacionadas à aproximação dos serviços às populações, adequando os serviços às condições de saúde de cada lugar, à formação e aperfeiçoamento contínuo dos recursos humanos e ao melhoramento e introdução de novas tecnologias. Dessa forma, a mortalidade geral em Cuba não é consequência das doenças da pobreza, mas, como nos países altamente desenvolvidos, das doenças do

\footnotetext{
${ }^{12}$ A taxa de mortalidade infantil é um indicador demográfico usado internacionalmente para mostrar de forma sintética os avanços das políticas públicas de desenvolvimento dos países. Ele reflete a qualidade dos serviços públicos do país, porque está ligada ao primeiro ano de vida, que é o mais critico para a sobrevivência do ser humanos. (OSA, 2011)
} 
coração, do câncer e dos acidentes cerebrovasculares. A expectativa de vida dos cubanos atinge hoje os 80 anos (LUNA et al, 2009; OSA, 2011).

Houve forte impuslo dado pela Revolução cubana à expansão da saúde pública no mundo: o que ficou conhecido como o internacionalismo em saúde. Como direito do povo e dever do Estado, é notória a contribuição que Cuba tem dado ao mundo no tocante ao fortalecimento da assistência à saúde. A colaboração em saúde pública de Cuba com outros países data do início da Revolução. Ramonet (2006), em entrevista a Fidel Castro, destaca:

\begin{abstract}
[...] O que a Revolução fez por nossa população pode ser expresso em números estatísticos que nenhum outro Estado foi capaz de mostrar. [...] Estamos lutando para criar o melhor capital médico do mundo. E não apenas para nós, mas para todos os povos da América Latina e outros povos do mundo. [...] Teremos dezenas de milhares de estudantes latino-americanos e caribenhos sob os princípios da ALBA (Alternativa Bolivariana para as Américas). (RAMONET, 2006, p. 602, tradução e grifo nosso)
\end{abstract}

No âmbito do que se denomina diplomacia da saúde, destaca-se a importância da atuação cubana exportando tecnologias inovadoras na área da biotecnologia e de equipamentos em saúde, disponibilizando recursos recursos humanos para sistemas de saúde reconhecidamente carentes de serviço qualificado, conduzindo estudos sobre diagnósticos em vários países e apoiando a elaboração o desenvolvimento de polígicas e programas de saúde pública nos países (BUSS \& FERREIRA, 2010; GÓMEZ, 2016).

A saúde ocupa o principal setor da cooperação internacional cubana desde 1962 com a inauguração do Instituto de Ciências Básicas “Victória de Girón”, quando Cuba decidiu brindar assistência médica aos países do Terceiro mundo, até o presente. Destaque para o Plano Integral de Saúde objeto de parceria com os países centro-americanos após a passagem do furação Mitch em 1998. Eis o que se persegue com o envio de médicos cubanos para outros países e, também, da educação em saúde, com a criação de uma escola de formação de médicos, garantida pelo Estado cubano, para estudantes estrangeiros. Essas são duas iniciativas que permite reconhecer o forte envolvimento do Estado socialista cubano com a cooperação Sul-Sul.

\title{
Médicos cubanos pelo mundo
}

O Programa de Internacionalismo Médico Cubano tem se notabilizado no mundo. Recentemente, a iniciativa de envio de médicos cubanos à situação emergencial de outros países foi indicada ao Prêmio Nobel da Paz em carta de nomeação pelo cientista canadense John W. Kirk em janeiro de 2015.

Na carta de indicação ${ }^{13}$, Kirk (2015) explica que, por mais de 5 décadas, Cuba fornece cooperação médica a dezenas de países em todo o mundo, inclusive a países cujos governos não possuem relações diplomáticas com Cuba, inspirados por José Martí que dizia que a pátria era a própria humanidade. Quando a África, em 2014, passou pela emergência de saúde trazida pelo vírus do Ebola, a Organização Mundial de Saúde (OMS) pode contar com assistência médica de urgência. Cuba foi o primeiro país a enviar

\footnotetext{
${ }^{13}$ John Kirk é professor de Estudos Latino-americanos da Universidade de Dalhousie em Halifax, Canadá; é co-autor de "Cuban Medical Internationalism: Origins, Evolution and Goals" (New York: Palgrave Macmillan, 2009) e autor de "Healthcare Without Borders: Understanding Cuban Medical Internationalism" (Gainesville: University Press of Florida, 2015). A carta original foi publicada em: http://resumen-english.org/2015/07/nobel-peace-prize-nomination-for-cuban-medical-internationalism-program/ Acesso em outubro de 2017.
} 
trabalhadores em ação humanitária e voluntária e se notabilizou pelo maior contingente de médicos (KIRK, 2015).

Dentre os logros no atual século XXI dos médicos cubanos pelo mundo estão: o Programa "Barrio Adentro" (2003) na Venezuela; a criação das brigadas médicas pelo mundo intitulada "Henry Reeve" (2005) que beneficiou o Paquistão após um terremoto e os Estados Unidos após o furação Katrina; a “Operação Milagre" (2004) para cirurgia de catarata realizada na Venezuela e depois nos demais países da ALBA; a criação dos Centro de Bem-Estar Infantil e do projeto "Crescendo com nossas crianças" em parceria com o Equador; da reestruturação do sistema de saúde do Haiti, em cooperação com o Brasil (2010) (KIRK, 2015; GÓMEZ, 2016; OSA, 2011).

Segundo aponta Gómez (2016), nesses mais de 50 anos, são aproximadamente 150 mil médicos colaboradores servindo em 108 países, sendo que, em 2014, eram 50 mil profissionais de saúde (médicos, enfermeiras e técnicos da saúde) em mais de 80 países. Trata-se de um contingente significativo de médicos servindo fora do país, o que tem sido conhecido muitas vezes como "exército batas brancas"14.

\section{A Escola Latino-Americana de Medicina}

Cuba concentra o maior número de médicos por habitante, a proporção é de um médico para cada 148 habitantes ou de 67,2 médicos para 10 mil habitantes, sendo 78.622 médicos no total, segundo a Organização Mundial da Saúde (OMS, 2010 apud TORRES e CRUZ, 2011).

Nos anos posteriores à Revolução, pretendeu-se melhorar o sistema nacional de saúde, o que demandaria a formação de grande quantidade de médicos. A ampliação e aperfeiçoamento do sistema de atendimento médico e hospitalar, o desenvolvimento da medicina preventiva, o impulso a medicina rural, o aumento dos estudos quanto à medicina do trabalho, o aumento da cultura sanitária do povo e a ênfase na prevenção do meio ambiente e dos bens naturais são algumas das diretrizes adotadas pela formação médica desse período. Assim, foi criada a Escola Cubana de Medicina (ELAM) reregida por 7 princípios - equidade, generosidade, solidariedade, acessibilidade, universalidade, responsabilidade e justiça (OSA, 2011).

Concebida em 1999, a ELAM é resultado do interesse cubano em fortalecer a capacidade dos países no âmbito das parcerias de cooperação internacional, contribuindo para a crise de recursos humanos em saúde, uma realidade global, e buscar a sustentabilidade e continuidade do trabalho das brigadas médicas pelo mundo. A Escola tem como missão formar médicos generalistas orientados a exercer a atenção primária em saúde e médicos capazes de atuar de acordo com as necessidades da região. Para tanto, foram estabelecidas quatro formações: atenção médica integral, educação, investigação e administração. O plano de estudo é flexivel para atender às diferentes realidades sanitárias do mundo (ELAM, 2014; GÓMEZ, 2016).

A ELAM se consagra hoje como uma oportunidade importante para muitos estrangeiros se formarem médicos em uma instituição pública e voltarem a seus países para prestação de serviço nos respectivos sistemas de saúde pública. Desde 1975, várias escolas de medicinas foram criadas em vários países que

\footnotetext{
${ }^{14}$ Expressão utilizada pelos próprios cubanos e formandos na ELAM, conforme pode ser encontrado no sítio da Escola disponível em http://instituciones.sld.cu/elam/ Acesso em fevereiro de 2017.
} 
puderam contar com professors cubanos - encabeçado por Yemen, estão Guiana, Etiópia, Guiné Bissau, Uganda, Gana, Guiné Equatorial, Eritréia, Gambia e Haiti (TORRES e CRUZ, 2011).

Poder-se-ía falar do largo alcance da Revolução cubana para o Sul global e de sua expressão humanista e, também, do exemplo de relações internacionais solidárias. Conforme comentou Osa (2011), as transformações e experiência acumulada por Cuba desde 1959, no âmbito científico, assistencial, de recursos humanos e materiais não ficaram circunscritas ao país e foram reconhecidas pela comunidade internacional. Nas palavras de Ban-Ki-Moon:

\begin{abstract}
Podemos identificar vários beneficios particulares deste programa. Primeiro, a formação médica segue padrões internacionais de excelência técnica. Segundo, o programa está orientado para as necessidades de países em desenvolvimento, concentrando-se nos elementos primários e preventivos da área rural e utilizando mais recursos humanos que tecnologia de alto custo. Terceiro, o programa é sistemático e aponta para a construção de um sistema de saúde público e não somente a provisão de capacitação médica de benefício individual. Quarto, o ethos distintivo da formação é que prepara os estudantes com espírito de trabalhadores de saúde pública comunitária em vez de empresários da saúde, isso, por sua vez, ajuda a reduzir o impacto da crônica 'fuga de cerébros' - uma perda, através da migração, de profissionais capacitados. (ANDERSON, 2006, p. 43, grifo e tradução nossa)
\end{abstract}

\title{
Considerações Finais: alguma inovação para a CID vinda de Cuba?
}

Ao convergir ideais socialistas, nos moldes latino-americanos, com os "sulistas", desde Martí até Fidel Castro, Cuba traz importantes contribuições para o mundo em desenvolvimento ao se caracterizar como uma país com bons indicadores sociais comparativamente. Mediante as lutas por ideiais nacionalistas e autonomistas, a união dos povos em desenvolvimento valoriza a própria conquista identitária e a apropriação de seu território. Isso faz a cooperação Sul-Sul ser uma prioridade em matéria de política externa cubana.

No âmbito das agendas globais de desenvolvimento - ODM e ODS, depara-se com alguns desafios. O caso cubano é revelador das iniciativas de cooperação internacional baseadas em princípios humanistas e solidários e, portanto, conectados aos objetivos finalísticos da parceria de CID, buscando contrapor-se aos modelos de cooperação internacional tradicional condicionados a outros objetivos, tanto implícitos quanto explícitos, de disputa de poder no âmbito da política externa.

Sobretudo, no tocante, ao campo da saúde coletiva, Cuba se notabiliza. Enquanto a mercantilização de serviços públicos é uma tendência crescente no centro dos países desenvolvidos, onde se assiste ao enfraquecimento do Estado de Bem-Estar Social face aos preceitos neoliberais do Consenso de Washington, Cuba continua sua resistência. Com base na oferta de uma formação de saúde atenta às distintas realidades humanas e aos ideiais humanitários, o país desenvolve paralelamente tecnologias sociais de baixo custo e cria centros de diagnósticos e de produção de fármacos de interesse público.

Os fatos recentes, desde 2011, anunciam mudanças nas diretrizes da política externa do país. Espera-se, para a cooperação internacional de Cuba, a intensificação de parcerias triangulares com presença de outros atores do Sul global, como o Brasil e a China, de bancos de desenvolvimento regional, como o do Caribe e o da África, os blocos regionais como a ALBA e a CELAC, além de organizações internacionais como 
o PNUD. Adicionalmente, mantém-se sua posição como beneficiário de arranjos de CID para apoiar seu desenvolvimento interno quanto a recursos humanos e institucionais e sua produção agrícola, da indústria biotecnológica e médica-farmacêutica.

A contribuição de Cuba para a Cooperação Sul-Sul está, além de sua resistência em se juntar às discussões da OCDE sobre a arquitetura da Eficácia da Ajuda, em conectar os valores e princípios vigentes desde a Revolução Cubana aos princípios formadores da CSS desde a Conferência de Buenos Aires. Sendo assim, cabe indagar em que medida o regime socialista consegue inovar nas iniciativas de CID.

Ao pensar a democracia, Boaventura de Sousa Santos (2016) afirma que Cuba oferece hoje uma oportunidade para a renovação de modelos de desenvolvimento dedicados ao bem-estar coletivo; dessa forma, permite pensar a esquerda a partir de um projeto reformador, pois introduz novos gurpos sociais até então esquecidos pela teoria crítica moderna e teoria marxista - autóctones, afrodescendentes, mulheres, camponeses.

Ademais, não se deve omitir sua participação nas propostas em prol do desenvolvimento sustentável. Michel Lowy (2007) cita Cuba como protótipo de país na marcha do ecossocialismo. Isso, porque não se trata nem de um planejamento não democrático e autoritário que dava o monopólio das decisões a uma oligarquia restrita de tecnoburocratas, como foi a União Soviética, nem da alienação capitalista, em que o tempo livre é trocado pelo consumismo incitado pela ideologia do "ter" sobre o "ser" e pela publicidade que cria novas necessidades ao ser humano. Segundo aquele autor, apesar de utópico, a consciência ecológica está intrinsecamente relacionada a tomadas de decisões socialistas ou comunistas, em que a auto-organização será resultado de uma transformação revolucionária.

Difícil se faz, entretanto, estabelecer uma relação direta entre o modelo de desenvolvimento socialista, presente o Estado cubano, e a plena realização da cooperação Sul-Sul, sem o amparo da pesquisa comparativa apoiada em dados qualitativos e variáveis quantitativas. No entanto, poder-se-ía analisar o Estado socialista cubano como um caso de cooperação Sul-Sul atípico e com grandes êxitos, ao ser intensivo em políticas sociais, com significativa e longeva experiência nas relações Sul-Sul, que valoriza a identidade "Sul global" e que possui na retaguarda referenciais intelectual-científicos úteis para o desenvolvimento de parâmetros analítocos diferentes dos vigentes nas atuais discussões da CID.

NOTA: Enquanto esse artigo era elaborado, o grande líder da Revolução cubana, Fidel Castro, deixou este mundo e, com sua partida, deve ficar nosso reconhecimento, povos latino-americanos e do Sul global que somos, pelo legado que nos deixou; também celebram-se os 50 anos da partida do Che Guevara que tanto se envolveu com a prática da cooperação Sul-Sul. Da singularidade e do papel que ainda ocupa Cuba projeta-se a esperança de renovação das propostas de desenvolvimento e de uma cooperação internacional mais comprometidos com o bem-estar humano. 


\section{REFERÊNCIAS}

AYLLÓN, A.P. A América Latina na Cooperação Internacional para o Desenvolvimento. In: Souza, A.M. (org.) Repensando a Cooperação Internacional para o Desenvolvimento. Brasilia, IPEA, 2014.

ANDERSON, M \& SMITH, L. The Cuban Heath Care System; 2006

BALLESTRÍN, L. América Latina e o Giro Decolonial. Revista Brasileira de Ciência Política. Brasília, n. 11, maio-agosto 2013 p. 89-117. Disponível em: http://www.scielo.br/scielo.php?script=sci_arttext\&pid=S0103-33522013000200004 Acesso em fevereiro de 2017.

BOBBIO, N. Dicionário de Política. Brasília: Ed. UnB, 2010. 13 ed.

BUSS, P. e FERREIRA, J.R. Ensaio crítico sobre a cooperação internacional em saúde. RECIIS, v. 4, n. 1, março, 2010 p. 93-105. Disponível em: http://www.reciis.icict.fiocruz.br/index.php/reciis/article/viewArticle/350. Acesso em: 20/12/2016.

CUBA. Constituición de la Republica de Cuba, aprovada em 1976 contendo as reformas de 1992. La Habana, Cuba, 1992.

CUBA. Escuela Latinoamericana de Medicina. Disponível em: http://www.sld.cu/sitios/elam/ Acesso em 20/12/2016.

GUEVARA, E. América Latina: despertar de un continente. La Havana: Inst. Cubano del Libro. 2014. 2 ed.

GÓMEZ, A.F.R. Cuba and South-South Cooperation. In: Reality of Aid Report "Country Case Studies on South-South Cooperation, 2016. p. 88-114

GONZÁLEZ, D. Solidariedad, compromisso y deber de retribución: médio siglo de interacción de Cuba con África perfilando el espírito de la cooperación. In: KABUNDA, M. (coord.) África y la cooperación con el Sur desde el Sur. Madrid: Ed. Catarata \& IUDC/UCM, 2011.

KABUNDA, M. (coord.) África y la cooperación con el Sur desde el Sur. Madrid: Ed. Catarata \& IUDC/UCM, 2011.

KICKBUSCH, I.; SILBERSCHMIDT, G.; BUSS, P. M. Global health diplomacy: the need for new perspectives, strategic approaches and skills in global health. Bull. WHO, v.85, n.3, p.230-2, 2007. Disponível em: http://www.who.int/bulletin/volumes/85/3/06-039222/en/ Acesso em outubro 2017.

GUNDER-FRANK, A. El Desarrollo del Subdesarrollo IN: CASAS, Garcia; ANGEL, Maria (ed) Antologia del Pensamiento Politico-Social y Económico de America Latina: La teoría de la Dependencia. Buenos Aires: Signos, 1970. 27-42 p

HOBSBAWN, E. A Era dos Extremos. São Paulo: Cia das Letras, 1995.

LEE, T. D; BREBRICK, L; MURRAY, D; SHALLUE, A; SULLIVAN-VEDDER, L (2005); Family Medicine in Cuba: Cummunity-Oriented Primary Care and Complementary and Alternative Medicine; The Journal of the American Board of Family Practice n.18, p.297-303, 2005.

LOWY, M. Ecossocialismo e planejamento democrático. Crítica Marxista, n. 28, 2009 p. 35-50. Disponível em: http://www.ifch.unicamp.br/criticamarxista/arquivos_biblioteca/artigo164Artigo3.pdf Acesso em 20/12/2016.

LUNA, E.C; PEREZ, D.C; SALABARRIA, L. La transformación del policlínico en Cuba de cara al siglo XXI. Rev Cubana Med Gen Integr., vol.25, n.2, 2009.

MARTÍ, J. Nossa América. Brasília: Ed. UnB, 2011. 
MEDINA, T.O. Cuba: 50 años de solidaridad con el Sur. IN: AYLLÓN, B. E OJEDA, T. (coords.) La cooperación Sur-Sur y triangular en América Latina: políticas afirmativas y prácticas transformadoras. Madrid: Ed. Catarata e UCM, 2013

ONU (ECOSOC) - Trends and Progress in international development cooperation. Report of the SecretaryGeneral. E/2014/77.

ONU (CEPAL) Horizontes 2030: la igualdad en el centro del desarrollo sostenible. Santiago, 2016

OSA, J.A de LA. Um olhar para a saúde pública cubana. Estududos Avançados vol.25, n.72, 2011. pp. 89-96. Disponível em: http://www.scielo.br/pdf/ea/v25n72/en_a08v25n72.pdf

PATRÍCIO, R.C. A Revolução Cubana, a deriva do regime castrista e os destinos de Cuba pós-Fidel Castro. Revista Meridiano 47. Brasília, n. 17, e.17021, 2017.

PNUD, Investigación sobre ciencia, tecnología y desarrollo humano en Cuba, 2003, p.117-119. http://hdr.undp.org/en/content/investigación-sobre-ciencia-tecnolog\%C3\%ADa-y-desarrollohumano-en-cuba-2003 Acesso setembro de 2017.

RAMONET, I. Cien Horas con Fidel. La Habana: Oficina de Publicaciones del Consejo de Estado, 2006. 2 ed.

RETAMAR, R.F. Pensamiento Anticolonial de Nuestra América. Colección Antologías del Pensamiento Social Latinoamericano y Caribeño. CLACSO, 2016.

ROMERO, A. Cuba, su política exterior y la nueva arquitetura de gobernanza regional en América Latina y el Caribe. Pensamento Próprio n. 42, 2015. Disponível em: http://www.cries.org/wpcontent/uploads/2015/12/010-romero.pdf Acesso em 20/12/2016.

SANTOS, B.S. A Difícil Democracia: reinventar as esquerdas. São Paulo: Boitempo, 2016.

SEGIB. 2016 Informe de la cooperación Sur-Sur en Iberoamerica. Madrid, Julio, 2016.

TORRES, N.M. e CRUZ, E.M. Experiencia cubana en Cooperación Sur-Sur. Rev. Cubana Salud Publica. Vol. 37, n. 4. La Habana: oct/dic. 2011. Disponível em: http://scielo.sld.cu/scielo.php?script=sci_arttext\&pid=S0864-34662011000400004 Acesso em setembro de 2014.

WINOCUR, M. História Social de la Revolución Cubana (1952-1959): las claeses olvidadas en el análisis histórico. México: UNAM e Hispanicas. 2 ed. 1989. 


\title{
RESUMO
}

Desde a Revolução de Cuba em 1959 o país tem vivido um regime de governo e um Estado baseado em princípios socialistas. Isso tem caracterizado a atuação do Estado tanto no plano interno, por meio da promoção de bens públicos, quanto no plano externo, por meio de parcerias de cooperação internacional com destaque para a grande participação no apoio a países e povos do Sul global em temas de interesse público que contribuem para o bem-estar social. O presente artigo analisa em que medida podemos dizer que a cooperação Sul-Sul se realiza num regime socialista de Estado, em especial a cooperação Sul-Sul em saúde: o "exército de batas brancas" cubano pelo mundo e a Escola Latino-americana de Medicina (ELAM).

Palavras-chave: Cuba; Cooperação Sul-Sul; socialismo; saúde; CID;

\begin{abstract}
Since the Cuban Revoluion of 1959, Cuba has been ruled by a political system based on socialist principles. That has carachterized the way the State develop its public policies inside and outside its' fronteers providing public goods for Cubans and also designing a Cuban foreign policy focused in partnerships with countries and peoples from the Global South and in areas of public interest that amounts to collective welfare. This papper discuss how a socialist regime can realize South-South Cooperation, especially the one dedicated to public health services: the so-called Cuban "White Army" around the world and also the Latin American Medical School (ELAM).
\end{abstract}

Key-words: Cuba; South-South Cooperation; Socialism; Health; IDC. 